\title{
Graduandos de sete cursos de saúde: entre transtornos mentais comuns e o rendimento acadêmico
}

\author{
Undergraduates from seven courses in the health area: common mental \\ disorders and academic performance
}
Graduados de siete cursos de salud: entre trastornos mentales comunes y desempeño académico

\begin{abstract}
Jansen Souza Moreira ${ }^{1}$, Ludwig Félix Machado Leal ${ }^{2}$, Laércia Maria Bertulina de Medeiros $^{3}$, Mísia Carolyne Pereira de Morais ${ }^{4}$
\end{abstract}

\footnotetext{
${ }^{1}$ Mestrando em Psicologia da Saúde pela Universidade Estadual da Paraíba. Campina Grande, Paraíba

${ }^{2}$ Mestrando em Psicologia Social pela Universidade Federal da Paraíba. João Pessoa, Paraíba

${ }^{3}$ Doutora em Ensino, Filosofia e História das Ciências pela Universidade Federal da Bahia. Docente do Departamento de Psicologia da Universidade Estadual da Paraíba. Campina Grande, Paraíba

${ }^{4}$ Mestranda em Psicologia Social pela Universidade Federal da Paraíba. João Pessoa, Paraíba
}

\section{RESUMO}

Objetivou-se investigar a qualidade de vida e o sofrimento psíquico em 254 graduandos de sete cursos de saúde da Universidade Estadual da Paraíba. Utilizou-se: questionário sociodemográfico; e questionário complementar com uma questão de múltipla escolha, quatro questões dicotômicas e duas questões abertas, elaboradas com base em indicadores gerais de Transtornos Mentais

Autor de Correspondência:

*Jansen Souza Moreira. E-mail: jan100sm@gmail.com 
Comuns - TMC, vivências acadêmicas e saúde, respectivamente. Os dados foram analisados por estatísticas descritivas no SPSS-23 e no GNU PSPP 1.0.1 (porcentagem, média e desvio-padrão). Como resultados, $61,2 \%$ não se sente satisfeito com o próprio rendimento acadêmico e 75,7\% relatou ansiedade. Análise de conteúdo explicitou sobrecarga e tempo reduzido para lazer e atividades físicas. Destaca-se a necessidade de identificação precoce de TMC nesta população, visando melhor desempenho pessoal e profissional, considerando a promoção de fatores de proteção e a possibilidade de serviços de apoio em saúde mental.

Palavras-chave: Estudantes de Ciências da Saúde. Saúde Mental. Qualidade de vida.

\begin{abstract}
The objective of this study was to investigate the quality of life and psychological suffering in 254 undergraduate students from seven health courses of Universidade Estadual da Paraíba. A sociodemographic questionnaire was used, in addition to a complementary questionnaire with a multiple-choice question, four dichotomous questions, and two open questions, elaborated based on general indicators of Common Mental Disorders, academic experiences and health, respectively. The data were analyzed using descriptive statistics in SPSS-23 and GNU PSPP 1.0.1 (percentage, mean, and standard deviation). The results showed that $61.2 \%$ are not satisfied with their academic performance, and $75.7 \%$ reported anxiety. Qualitative analysis indicated overload, and reduced time for leisure and physical activities, for example. The need for early identification of Common Mental Disorders in this population is highlighted, aiming at better personal and professional performance, considering the promotion of protective factors and the possibility of mental health support services.
\end{abstract}

Keywords: Students, Health Occupations. Mental Health. Quality of Life

\title{
RESUMEN
}

Se investigó la calidad de vida y el sufrimiento psicológico en 254 estudiantes de pregrado de siete cursos de salud en la Universidad Estatal de Paraíba. Se utilizó: cuestionario sociodemográfico; y cuestionario complementario con una pregunta de opción múltiple, cuatro dicotómicas y dos abiertas, elaborado en base a indicadores generales de Trastornos Mentales Comunes DMC, experiencias académicas y salud, respectivamente. Se realizaron estadísticas descriptivas en SPSS-23 y GNU PSPP 1.0.1 (porcentaje, media y desviación estándar). Como resultado, el $61.2 \%$ no está satisfecho con su rendimiento académico y el $75.7 \%$ reportó ansiedad. El análisis de contenido indicó la sobrecarga y el tiempo reducido para el ocio y las actividades físicas. Se destaca la necesidad de una identificación temprana de TMC en esta población, con el objetivo de un mejor desempeño personal y profesional, considerando la promoción de factores protectores y la posibilidad de servicios de apoyo para la salud mental.

Palabras clave: Estudiantes del Área de la Salud. Salud Mental. Calidad de Vida 


\section{INTRODUÇÃO}

O advento da contemporaneidade tem estado relacionado a um aumento na prevalência de sofrimento mental, também referido como adoecimento psíquico ou como problemas psicológicos, que por sua vez têm efeitos negativos em muitos aspectos da vida, interferindo nos relacionamentos interpessoais, na motivação, no prazer de viver, e, não raro, impedindo o pleno exercício das atividades cotidianas ${ }^{1}$. São estados emocionais com repercussões físicas que se manifestam em diferentes níveis e com ampla sintomatologia, por vezes inespecífica, incluindo depressão, ansiedade, queixas somáticas, etc., referidos comumente na literatura enquanto Transtornos Mentais Comuns - TMC $2,3,4,5,6,7,8$.

Estes apresentam maior incidência durante a transição para a vida adulta, e podem ser desencadeados ou agravados por determinados contextos, como o período universitário ${ }^{5}$. Vale ressaltar que a universidade não é isoladamente responsável pelo sofrimento psíquico dos discentes, considerando-se também cada histórico de vida, suas condições sócio-históricas, percebidas e vivenciadas tanto coletivamente quanto individualmente, de modo que estes podem chegar ao ambiente acadêmico carregando e enfrentando diversas fragilidades e sofrimentos ${ }^{1}$.

A preocupação pública com o adoecimento psíquico discente tem aumentado nas últimas décadas, havendo diversos estudos nacionais, sobretudo com estudantes da área da saúde 9,10,11,12,13,14,15,16,17,18. Tais cursos, por envolverem o contato direto e estendido com pessoas em sofrimento, encontra destaque nessa temática, e a incidência de TMC vem sendo relacionada a prejuízos no humor, no raciocínio e no comportamento, afetando a aprendizagem e o rendimento acadêmico, podendo aumentar os erros nas práticas clínicas e nos estágios, dificuldades com docentes, colegas de sala e pacientes, ocasionando afastamentos, desistências e até tentativas de suicídio.

Complementarmente, os estressores da rotina acadêmica, a quantidade de novas informações, a carga horária excessiva, as escolhas e decisões do percurso profissional, a procedência geográfica, as condições de habitação e alimentação, as cobranças avaliativas, enfim, uma série de aspectos adjacentes são concatenados nesse período, e podem pesar nos processos de saúde-doença ${ }^{10,1}$. Compreende-se que estudantes de nível superior vivenciam tanto mudanças biológicas quanto psicológicas e sociais, em seu processo de adaptação a esse novo estágio da vida, e que estas podem vir a ser promotoras de bemestar, mas também de enfermidades ${ }^{12}$.

O ensino superior é responsável pela formação técnica e científica dos futuros profissionais que prestarão ampla gama de serviços laborais na sociedade. Logo, as instituições superiores e as políticas públicas não podem demonstrar despreparo sobre o assunto, muito menos coadunar com o desamparo e a negligência aos estudantes, tanto a nível público quanto privado ${ }^{10}$. Reconhecendo as dificuldades enfrentadas por esses sujeitos, é possível auxiliar na prevenção e na superação dos momentos de crise, promover intervenções visando um melhor desempenho pessoal e profissional do corpo discente, considerando a identificação precoce e a manutenção das redes de apoio social ${ }^{5,12,1}$.

Assim, a presente pesquisa objetivou investigar a Qualidade de Vida - QV e o sofrimento psíquico dos estudantes do Centro de Ciências Biológicas e da Saúde - CCBS da Universidade Estadual da Paraíba - UEPB, identificando a possível incidência de Transtornos Mentais Comuns - TMC.

\section{Saúde e Transtornos Mentais Comuns}

A mudança no perfil de morbimortalidade das 
sociedades atuais, com relação às doenças crônicas-degenerativas, traz consigo a exigência de referenciais teóricos que incluam os determinantes sociais da saúde junto às clássicas noções biomédicas, tendo em vista a ausência de consenso conceitual acerca do que seria saúde, QV, bemestar, etc., devido à natureza complexa, subjetiva e multideterminada à qual se remetem, irredutível à mera ausência de doenças ${ }^{19-21}$.

Além disso, é mister considerar também que os indicadores adotados nas diversas abordagens e suas possibilidades de operacionalização e avaliação se apresentam diretamente relacionados aos interesses científicos e políticos de cada estudo e área de investigação $0^{22,23}$.

No presente estudo será admitida uma noção polissêmica da QV, numa abordagem psicológica, levando-se em conta a própria avaliação dos indivíduos sobre sua satisfação em diferentes âmbitos de sua vida, seus objetivos, expectativas, preocupações, etc. Não se ignora, todavia, que tal avaliação está inserida num contexto cultural histórico específico, ou seja, decanta nas construções sociais próprias de seu tempo e espaço, e seus sistemas de valores, axiológicos ${ }^{19,20,23}$.

Complementarmente, citam-se aqui os transtornos mentais não psicóticos, fora da nosologia psiquiátrica considerada grave, mas nem por isso desprovidos de efeitos negativos na QV da população adulta brasileira $^{8}$. Estes podem ser referidos por diversas terminologias, no presente estudo serão referidos como Transtornos Mentais Comuns - $\mathrm{TMC}^{6}$, que se referem a manifestações de perturbação caracterizadas pela presença de depressão, ansiedade, insônia, queixas somáticas, entre outras ${ }^{3,4,8}$.

O conceito de TMC se constitui num modelo dimensional, que se baseia na relação entre sintomas individuais, admitindo um continuum e uma comorbidade entre diversas categorias diagnósticas, até mesmo com uma indiferenciação entre alguns dos sintomas, o que o afasta das normas estritas dos manuais psiquiátricos, cujo modelo, este categorial, é baseado na coleção de sintomas observados pelos clínicos, ou seja, eminentemente sindrômico, estabelecendo muitas vezes pontos de corte arbitrários, com suas devidas vantagens e desvantagens ${ }^{4}$.

Já quanto aos fatores sociodemográficos relacionados aos TMC, aponta-se, por exemplo, para uma estreita relação entre estes e o perfil socioeconômico, com maior incidência em sujeitos ou grupos expostos às vulnerabilidades decorrentes da baixa renda, e também maior incidência conforme menor densidade da rede de apoio social, tendo assim com esta uma relação inversamente proporcional ${ }^{3}$. O uso do termo TMC, então, apesar de carregar consigo algumas críticas, como a possível psiquiatrização da vida e uma postura medicalizante, na realidade vem apontando para seu uso em pesquisas que comumente consideram a ligação entre estas manifestações de sofrimento e seus enlaces psicossociais ${ }^{3,8}$.

\section{MÉTODO}

Trata-se de um estudo de campo, observacional, exploratório, descritivo, de corte transversal, ex post facto, com abordagem quantitativa ${ }^{24}$.

A amostra foi composta por uma estratégia acidental não probabilística, por conveniência ${ }^{25}$, na qual o critério de inclusão foi estar matriculado nos semestres intermediários ( $3^{\circ}$ ano), evitando-se assim os novatos e os concluintes, estes, sujeitos a estressores específicos de tais processos. A UEPB abrange pouco mais de 15.000 alunos, o CCBS, por sua vez, engloba cerca de 2.500 destes, e o número amostral foi de 254 (aprox. 10\%), dos cursos: 
psicologia, fisioterapia, odontologia, farmácia, enfermagem, educação física e biologia.

Um estudo piloto foi realizado no intuito de obter dados confiáveis, assim como para realizar possíveis aperfeiçoamentos nos instrumentos, e contou com a participação de 35 estudantes do CCBS, não sendo tais respostas computadas no estudo principal.

A coleta de dados foi realizada entre outubro de 2019 e fevereiro de 2020, após parecer favorável ( $n^{\circ} 3.621 .171$ ) do comitê de ética (CAAE: 17922618.2.0000.5182). Os participantes foram abordados nas dependências do campus I, informados dos objetivos, do caráter confidencial das respostas e voluntariedade da participação, em conformidade com os aspectos éticos previstos na Resolução № 466/MS de 2012. Aqueles que se dispuseram a participar assinaram um Termo de Consentimento Livre e Esclarecido - TCLE. O preenchimento dos instrumentos teve duração média de 15 minutos.

Foram utilizados dois instrumentos para a coleta dos dados. Um questionário sociodemográfico, com questões versando sobre idade, curso, período letivo, cidade de residência e de origem, estado civil e sexo. Um questionário complementar com quatro questões dicotômicas tipo sim/não, sobre sensação de envolvimento com o curso, satisfação com o próprio rendimento acadêmico, se a carga horária afeta a qualidade de vida, e uso de serviços de psicologia; uma questão de múltipla escolha com sintomas gerais referentes aos TMC, e duas questões abertas, uma sobre uso de substâncias lícitas/ilícitas, e uma sobre as dificuldades percebidas na vida acadêmica.

Os dados foram analisados por meio de estatísticas descritivas, incluindo medidas de tendência central (média) e de dispersão (desvio-padrão), além de frequências e porcentagens. Para tanto, foram processados em forma de banco de dados nos programas Statistical Package for the Social Sciences SPSS-23 e GNU PSPP (versão 1.0.1).
Para a análise dos dados referentes à questão aberta sobre as principais dificuldades percebidas na via acadêmica, utilizou-se a análise de conteúdo temático-categorial26, por tratar do desmembramento do discurso em categorias a partir dos temas relacionados ao objeto de pesquisa, identificados nos discursos dos participantes. Esta seguiu uma sequência de procedimentos que incluiu: pré-análise das respostas obtidas na questão aberta do questionário semiestruturado, sobre suas dificuldades na vida acadêmica, seguida da exploração do material e tratamento dos resultados por inferência e interpretação. Realizouse inicialmente uma leitura flutuante do material de análise, em seguida foram identificadas e codificadas as categorias empíricas existentes nas respostas dos sujeitos. Esta etapa foi realizada por meio de discussão quanto à adequação das categorias, por parte de dois juízes, da área da psicologia e com experiência no tema. Por fim, os resultados obtidos foram diagramados e interpretados.

\section{RESULTADOS E DISCUSSÃO}

Pela análise sociodemográfica, a idade variou entre 18 e $43(\mathrm{M}=21,8$; $\mathrm{DP}=3,5)$, a maioria mulheres (64,3\%), na condição solteira (93\%), sendo aproximadamente 50\% de Campina Grande - PB. Entre os que não apontam o curso atual como primeira opção, somase $58,4 \%$, 31\% tem alguma experiência em outro curso superior; $84,7 \%$ se sente envolvido com o curso, e $38,8 \%$ está satisfeito com seu rendimento acadêmico.

Paralelamente, $73,7 \%$ afirmou que a carga horária semanal da universidade afeta sua QV, conquanto apenas $21,6 \%$ já frequentou algum serviço de psicologia, e 22,4\% declarou fazer uso de alguma substância (lícita ou ilícita) buscando amenizar sintomas de TMC. Houve quatro 
tipos de substâncias ilícitas relatadas, em ordem decrescente: cannabis, cocaína, "loló" e "LSD", enquanto entre as substâncias lícitas foram relatadas: álcool, tabaco, cafeína, estimulantes, ansiolíticos, antidepressivos, analgésicos, calmantes, anti-inflamatórios, fitoterápicos e florais; entre medicações especificamente citadas estão: ritalina, rivotril, torsilax, dorflex, paracetamol, dipirona e omeprazol. Resultados complementares, divididos por cursos, podem ser vistos na Tabela 1 a seguir.

Tabela 1 - Porcentagem de discentes, por curso, que responderam afirmativamente às respectivas questões dicotômicas $(\mathrm{n}=253)$.

\begin{tabular}{l|c|c|c|c|c|c|c}
\hline & Bio. & $\begin{array}{c}\text { Ed. } \\
\text { Física }\end{array}$ & Enf. & Far. & Fisio. & Odonto. & Psi. \\
\hline $\begin{array}{l}\text { Curso atual não foi a } \\
\text { primeira opção }\end{array}$ & $58,5 \%$ & $47,4 \%$ & $63,6 \%$ & $58,3 \%$ & $58,8 \%$ & $60 \%$ & $54,1 \%$ \\
\hline $\begin{array}{l}\text { Carga horária tem } \\
\text { afetado a QV }\end{array}$ & $68,3 \%$ & $31,6 \%$ & $84,8 \%$ & $83,3 \%$ & $91,2 \%$ & $76,7 \%$ & $70,3 \%$ \\
\hline $\begin{array}{l}\text { Já utilizou algum serviço } \\
\text { de psicologia }\end{array}$ & $14,6 \%$ & $5,3 \%$ & $12,1 \%$ & $18,8 \%$ & $17,6 \%$ & $20 \%$ & $59,5 \%$ \\
\hline $\begin{array}{l}\text { Sentir-se envolvido com } \\
\text { o curso }\end{array}$ & $78 \%$ & $89,5 \%$ & $78,8 \%$ & $81,3 \%$ & $82,4 \%$ & $90 \%$ & $81,1 \%$ \\
\hline $\begin{array}{l}\text { Satisfação com o } \\
\text { rendimento acadêmico }\end{array}$ & $26,8 \%$ & $55,3 \%$ & $45,5 \%$ & $37,3 \%$ & $32,4 \%$ & $33,3 \%$ & $35,1 \%$ \\
\hline
\end{tabular}

Fonte: os autores (2020).

Quanto aos TMC, mais da metade da amostra relatou ansiedade $(75,7 \%)$, fadiga $(68,2 \%)$, irritabilidade (67,1\%), dificuldade de concentração (63,1\%), alterações no apetite $(55,3 \%)$ e desmotivação $(54,9 \%)$. Outros sintomas também foram demarcados, como dores musculares (49\%), lapsos e esquecimentos $(43,5 \%)$, cefaleia $(46,7 \%)$, insônia $(33,3 \%)$, tristeza excessiva $(26,7 \%)$, enxaqueca $(25,1 \%)$, pesadelos $(23,5 \%)$, confusão mental $(22 \%)$, gastrite nervosa $(20,8 \%)$, sudorese $(20,4 \%)$, tremores $(19,2 \%)$, medo excessivo $(18,8 \%)$, dor abdominal $(18 \%)$, taquicardia
$(15,7 \%)$, falta de ar $(11,8 \%)$, e pânico $(7,8 \%)$. Na tabela 2 é possível observar tais resultados, divididos por cursos.

Já a análise de conteúdo das entrevistas, a partir do procedimento de análise do tipo categorial temática ${ }^{26}$, baseou-se numa questão aberta que perguntou aos estudantes quais as suas principais dificuldades na vida acadêmica, e evidenciou a emergência de 251 unidades de conteúdo, as quais compuseram três categorias temáticas e 11 subcategorias. Estes resultados são apresentados na Tabela 3. 
Tabela 2 - Porcentagem de discentes, por curso, que relataram sintomas de TMC $(\mathrm{n}=252)$.

\begin{tabular}{c|c|c|c|c|c|c|c}
\hline & Bio. & $\begin{array}{c}\text { Ed. } \\
\text { Física }\end{array}$ & Enf. & Far. & Fisio. & Odonto. & Psi. \\
\hline Ansiedade & $82,9 \%$ & $42,1 \%$ & $78,8 \%$ & $72,9 \%$ & $82,4 \%$ & $70 \%$ & $75,7 \%$ \\
\hline Fadiga & $73,2 \%$ & $52,6 \%$ & $87,9 \%$ & $66,7 \%$ & $58,8 \%$ & $56,7 \%$ & $70,3 \%$ \\
\hline Irritabilidade & $80,5 \%$ & $39,5 \%$ & $78,8 \%$ & $58,3 \%$ & $76,5 \%$ & $56,7 \%$ & $70,3 \%$ \\
\hline $\begin{array}{c}\text { Dificuldades de } \\
\text { concentração }\end{array}$ & $65,9 \%$ & $50 \%$ & $72,7 \%$ & $62,5 \%$ & $52,9 \%$ & $53,3 \%$ & $73 \%$ \\
\hline $\begin{array}{c}\text { Alterações no apetite } \\
\text { Desmotivação }\end{array}$ & $58,5 \%$ & $39,5 \%$ & $57,6 \%$ & $52,1 \%$ & $61,8 \%$ & $43,3 \%$ & $64,9 \%$ \\
\hline Dores musculares & $36,6 \%$ & $44,7 \%$ & $51,5 \%$ & $37,5 \%$ & $70,6 \%$ & $40 \%$ & $59,5 \%$ \\
\hline Lapsos/esquecimentos & $39 \%$ & $36,8 \%$ & $57,6 \%$ & $41,7 \%$ & $52,9 \%$ & $26,7 \%$ & $43,2 \%$ \\
\hline Cefaleia & $43,9 \%$ & $21,1 \%$ & $69,7 \%$ & $43,8 \%$ & $55,9 \%$ & $33,3 \%$ & $54,1 \%$ \\
\hline Insônia & $48,8 \%$ & $28,9 \%$ & $33,3 \%$ & $29,2 \%$ & $29,4 \%$ & $30 \%$ & $27,8 \%$ \\
\hline
\end{tabular}

Fonte: os autores (2020).

Tabela 3 - Dificuldades na vida acadêmica de graduandos da saúde $(\mathrm{n}=251)$.

\begin{tabular}{|c|c|c|c|}
\hline \multirow[t]{2}{*}{ Categorias } & \multirow[t]{2}{*}{ Subcategorias } & $\begin{array}{l}\text { Unidades de } \\
\text { Conteúdo }\end{array}$ & $\begin{array}{l}\text { Unidades de } \\
\text { Conteúdo }\end{array}$ \\
\hline & & $\mathrm{F}$ & $\%$ \\
\hline \multirow{2}{*}{ Sofrimento psíquico } & Ansiedade & 19 & \multirow{2}{*}{20,3} \\
\hline & Estresse & 32 & \\
\hline \multirow{3}{*}{ Sobrecarga e exaustão } & Carga horária excessiva & 21 & \multirow{3}{*}{23,9} \\
\hline & Cansaço e outros sintomas físicos & 24 & \\
\hline & Dificuldade de conciliar diferentes atividades & 15 & \\
\hline \multirow{6}{*}{ Tempo reduzido } & Atividades extra-curriculares & 35 & \multirow{6}{*}{55,7} \\
\hline & Qualidade do sono & 31 & \\
\hline & Qualidade da alimentação & 17 & \\
\hline & Descanso e lazer & 16 & \\
\hline & Relações sociais & 26 & \\
\hline & Atividades físicas & 15 & \\
\hline Total & 251 & \multicolumn{2}{|c|}{100} \\
\hline
\end{tabular}


Como descrito anteriormente, entre os sintomas mais relatados, ansiedade obteve a maior porcentagem (75,7\%), o que reforça a atenção para este constructo. Outrossim, 33,3\% da amostra relatou insônia, e 23,5\% relatou pesadelos. Além disso, conforme apresentado na Tabela 3, o tempo reduzido, principal dificuldade na vida acadêmica para mais da metade da amostra $(55,7 \%)$, foi colocado como fator de interferência negativa na qualidade do sono, na prática de atividades físicas e nas relações sociais, o que pode acarretar em prejuízo na QV.

Resultados similares podem ser observados em uma pesquisa ${ }^{13}$ que avaliou, dentre outras coisas, o nível de ansiedade numa amostra de 476 estudantes de cursos da área de saúde, verificando uma incidência de $36,1 \%$, mais associada às mulheres, aos estudantes com relacionamento insatisfatório com familiares e colegas, com sedentarismo e com má qualidade do sono, sendo maior no curso de fisioterapia, cujo índice de ansiedade foi de $52,4 \%$. Os autores descrevem também que mais da metade de sua amostra $(67,9 \%)$ afirmou que seu curso foi a primeira opção profissional, e 98,9\% confirma sua satisfação com o mesmo.

Por outro lado, no presente estudo $82,4 \%$ afirma estar envolvido com seu curso, e menos da metade (41,2\%) confirma este como primeira opção profissional, de maneira que a maioria dos universitários aqui pesquisados não optou primeiramente pelo curso no qual está atualmente matriculado, o que pode ser uma das explicações para os quase 15\% que não se sentem envolvidos com sua graduação.

Pesquisadores $^{27}$ avaliaram a QV e indicativos de ansiedade e depressão em 238 universitários portugueses de oito cursos, das áreas de saúde, humanas e exatas, e observaram que as mulheres apresentaram maior motivação, melhor qualidade de sono e de relações interpessoais, enquanto homens uma maior prática de exercícios físicos, não havendo diferenças estatisticamente significativas para estresse e ansiedade entre os sexos; havendo, contudo, para depressão, sendo a maior média para eles. Os autores verificaram também que os estudantes que saíram da casa de sua família para ingressarem na academia, residindo assim com outros colegas ou em residências universitárias, demonstraram maiores níveis de ansiedade, depressão e estresse, além de menor média para todas as dimensões da QV (ambiental, físico, psicológico e social), inclusive para qualidade de sono, gestão do tempo, prática de exercícios físicos e relações interpessoais.

Tais resultados ressaltam as dificuldades enfrentadas pelos universitários que precisam superar distâncias e adaptações em novos ambientes de moradia. Sobre o tema, no presente estudo cerca de $50 \%$ da amostra declarou residir em Campina Grande, exigindo menores deslocamentos para a rotina universitária, condição não aplicável à outra metade da amostra que afirmou procedência de vários outros estados do Nordeste, inclusive de outras regiões do País, contando com os desafios da procedência geográfica no cotidiano acadêmico destes estudantes, outro possível fator de interferência tanto na QV quanto no rendimento acadêmico.

Como descrito no início desta secção, em média menos da metade da amostra $(38,8 \%)$ se mostrou satisfeita com o próprio rendimento acadêmico, e a maioria (73,7\%) declarou que a carga horária semanal da universidade tem afetado sua QV, com exceção para o curso de educação física, com índices de 55,3\% e $31,6 \%$, respectivamente, sendo também onde mais estudantes (50\%) relataram ter sido esta sua primeira opção de curso.

Ao avaliar relações entre a $\mathrm{QV}$ e o índice de rendimento acadêmico - IRA de 492 universitários em cursos na área de humanas, exatas e da saúde, uma pesquisa constatou maior média geral na QV associada a uma maior média no IRA apenas para a área de humanas, enquanto menor em ambas as variáveis para a área de exatas, sendo pior na área 
da saúde, especificamente para os fatores físico, relações sociais e meio ambiente ${ }^{28}$. Foi verificado também que, para este último fator da $\mathrm{QV}$, uma menor média esteve estatisticamente relacionada a um maior IRA para os estudantes da área de saúde. Ainda no domínio do fator meio ambiente da QV, houve correlação positiva significativa entre o IRA e a disponibilidade de recursos financeiros, o que pode explicar parte dos resultados uma vez que os cursos da área de saúde costumam ser financeiramente mais dispendiosos. Apesar das análises por áreas de conhecimento, os autores ressaltam a possível existência de especificidades entre os cursos, o que de fato não pode ser descartado.

Numa amostra de 640 graduandos de todo o Brasil, foi constatada uma correlação negativa estatisticamente significativa entre as vivências acadêmicas e a vulnerabilidade psicológica, aqui definida como presença de sintomas indicativos de ansiedade, estresse e depressão $0^{29}$. Ou seja, quanto pior a percepção dos estudantes em relação às suas experiências dentro da universidade, maior o risco de TMC. Os autores concluem que ter e manter percepções positivas sobre as próprias habilidades e competências para estudar, aprender e gerir o tempo, podem se constituir enquanto fatores protetivos da saúde mental. Além disso, reforçam que não manter uma boa relação com colegas pode prejudicar o estabelecimento da sua rede de apoio no contexto acadêmico, que por sua vez pode acarretar em sentimentos de não pertencimento e dificuldades de adaptação, propícios também aos TMC.

Apesar de, como supracitado, na presente pesquisa mais de $75 \%$ ter relatado sintomas de ansiedade, além de outros sofrimentos difusos, apenas 21,6\% afirmou já ter frequentado algum serviço especializado de psicologia, como a clínica-escola do curso de psicologia no próprio CCBS. Entre os estudantes deste curso, contudo, a média sobe para 59,5\%, sendo a segunda maior para odontologia, apenas
$20 \%$, índices pequenos considerando a amplitude sintomatológica observada na amostra.

Em um estudo com 246 graduandos de todas as áreas do conhecimento, constatou-se que apenas 19,2\% havia recebido algum tipo de atendimento em saúde mental, em contrapartida $45 \%$ já pensou em abandonar o curso, mesmo que 90,6\% tenha admitido satisfação com a escolha profissional. Os autores observaram uma prevalência geral de $40 \%$ de TMC, que se mostrou associada ao sexo (mulheres), à insatisfação com o curso, às relações interpessoais insatisfatórias e à percepção de pouco apoio emocional ${ }^{7}$.

Pesquisadores avaliaram a QV em 630 graduandos de quatro cursos da área da saúde, e verificaram que o domínio com melhor escore foi a capacidade funcional, enquanto o pior foi vitalidade ${ }^{16}$. Além disso, a escassez de tempo livre e o cansaço foram apontados pelos universitários como principais dificuldades, corroborando os resultados aqui apresentados, como pode ser visto na Tabela 3, sendo as principais categorias relatadas quanto às dificuldades da vida acadêmica: a sobrecarga/ exaustão e o tempo reduzido. Complementarmente, a fadiga enquanto sintoma também foi especificamente relatada, com índice geral de $68,2 \%$, chegando a $87,9 \%$ para estudantes de enfermagem.

Em uma avaliação feita sobre a QV em 253 graduandos de cursos na área da saúde, evidenciou-se maior prejuízo no fator meio ambiente da QV, sendo renda um preditor estatisticamente significante ${ }^{11}$. Também se verificou, entre 320 graduandos da área de saúde, insatisfação na QV destes no fator meio ambiente, assim como no domínio psicológico e de relações sociais 9

Relata-se ainda que a maioria afirmou consumir bebidas alcoólicas, e, apesar de avaliarem o consumo de substâncias ilícitas como "baixo", constatou-se que a cannabis é a mais utilizada ${ }^{11}$. Foi verificada em 
outra pesquisa ${ }^{28}$ a presença de correlação negativa entre o consumo do tabaco e o IRA, de modo que quanto maior o consumo diário de cigarros, menor se mostrou o IRA do graduando em questão, sendo importante aqui pontuar que correlação não supõe causalidade 4 . Em outro estudo, o consumo de bebida alcoólica não apresentou relações estatisticamente significativas com ansiedade, mas foi relatado por 53,4\% da amostra, enquanto o hábito de fumar foi relatado apenas por $3,2 \%{ }^{13}$. Tais estudos apresentam resultados próximos aos encontrados na presente pesquisa, onde quase metade (45\%) relatou consumo de álcool, e uma parcela significativa (18\%) fuma, sendo também a cannabis a substância ilícita mais relatada.

Considerando os $22,4 \%$ que afirmaram uso de alguma substância, lícita ou ilícita, visando amenizar o sofrimento difuso dos TMC, os medicamentos foram os mais relatados, destacando-se os ansiolíticos, antidepressivos e analgésicos, levando-se em conta que $49 \%$ relatou dores musculares.

Nessa direção, outros autores avaliaram a sintomatologia de transtornos de ansiedade em 111 graduandos que foi associada ao consumo de medicamentos, verificando o maior uso de fitoterápicos (37,5\%), antidepressivos (37,5\%), e ansiolíticos (24\%), sendo que $36 \%$ afirmou já ter feito uso pontual ou esporádico de algum medicamento para fins ansiolíticos ${ }^{14}$. Os autores relataram um total de $70 \%$ com sintomatologia moderada ou grave para os transtornos de ansiedade, e dividiram os índices pelo sexo, obtendo dados indicando que entre mulheres, $22 \%$ obteve escore leve, $46 \%$ moderado e $32 \%$ grave, enquanto entre homens, $48 \%$ leve, $43 \%$ moderado e $9 \%$ grave.

Medicamentos como o omeprazol e o lanzopept foram citados pelos graduandos da presente pesquisa, somado ao fato de que $18 \%$ relatou dor abdominal e $20,8 \%$, gastrite nervosa. Pesquisadores analisaram a frequência de Doença do Refluxo Gastroesofágico -
DRGE e relações com a QV entre 464 estudantes de cursos na área da saúde, concluindo que a DRGE é uma afecção comum entre graduandos e que por sua vez tem relações com o acometimento de todos os domínios da QV. Os autores descrevem a presença de diferenças estatisticamente significativas em todos os fatores da QV ao se comparar sujeitos com $(40,1 \%)$ e sem DRGE ${ }^{17}$.

Estudou-se também o impacto da cefaleia na QV de 298 graduandos da área da saúde, verificando que a ocorrência de tal sintoma parece ser influenciada tanto por fatores genéticos e hormonais quanto por fatores comportamentais ${ }^{15}$. Os autores relataram que todos os domínios da QV foram estatisticamente menores entre os universitários com cefaleia de alto impacto, sendo mais presente entre as mulheres, e estando associada também à baixa renda (até três salários) e à qualidade da alimentação, de modo que a disposição de comer menos do que deseja se comportou como fator de proteção. Tais dados podem ser vistos em paralelo ao citado pela amostra do presente estudo, a qual relatou também enxaqueca $(25,1 \%)$ e cefaleia $(46,7 \%)$, enquanto a qualidade da alimentação foi uma das seis subcategorias relatadas como prejudicadas pela falta de tempo, conforme consta na Tabela 3.

Ainda na Tabela 3, percebe-se que o tempo reduzido devido, dentre outras coisas, à carga horária acadêmica, prejudica a prática de exercícios físicos, e de maneira complementar a sobrecarga/exaustão dificulta a conciliação entre diferentes atividades, todos fatores que podem ser considerados na QV dos universitários.

Em uma revisão da produção acadêmica sobre atividades físicas e a vida universitária, concluiuse que a literatura apresenta consenso sobre seus benefícios nessa população, conquanto verificouse um baixo nível dessa prática, o que ressalta necessidade de ações em promoção da saúde nesse escopo, considerando que os hábitos e o estilo de 
vida dos sujeitos dependem de diversos fatores ambientais, sociais, demográficos e culturais ${ }^{30}$. Outros autores, ao avaliarem o perfil de risco para doenças cardiovasculares em estudantes universitários, destacam o sedentarismo, relatado por $60 \%$ da amostra, como fator de risco, associado à hiperglicemia, hipertensão e um índice de massa corporal elevado. Paralelamente, $37,7 \%$ das mulheres apresentou TMC, contra $17 \%$ entre os homens, compondo um conjunto de considerações que exigem atenção e, comumente, mudanças nos hábitos do estilo de vida para ambos os sexos, visando melhora e manutenção da $\mathrm{QV}^{31}$.

Na Tabela 3, a falta de tempo para descanso e lazer também foi uma dificuldade relatada, e não pode ser desconsiderada. Em uma revisão da produção científica sobre lazer entre universitários da área da saúde, observou-se que, dentre outras coisas, a ingestão de álcool no âmbito do lazer é bastante mencionada, o que gera atenção e cuidado. Relatase também uma visão limitada do lazer em grande parte das produções, a ponto de restringirem o termo às práticas corporais, como as atividades desportivas ${ }^{32}$. Contudo, outras formas de lazer foram também observadas na literatura, como as sociais, intelectuais e artísticas, consideradas também promotoras de saúde, de maneira que seu incentivo possa promover uma cultura e educação voltadas ao lazer como estratégia para manutenção da QV.

A experiência de um serviço de apoio em saúde mental para estudantes da área da saúde apontou que a prevalência das demandas, com dados entre 2009 e 2015, é de transtornos depressivos (32\%), seguidos dos transtornos ansiosos (27\%). Além disso, observouse um aumento nos novos casos acompanhados, passando de 43 em 2009 para 62 em 2015, sendo as principais dificuldades apontadas pelos estudantes, a adaptação à nova cidade ou à distância da família, mudanças na forma de estudar e gerenciamento do próprio tempo ${ }^{18}$. Dentre os obstáculos encontrados na efetividade deste serviço, apontou-se a insuficiência de recursos humanos e a necessidade de se incluir na abordagem os familiares e amigos/colegas para promoção de um tratamento integral.

Em outro estudo, também foi avaliado um serviço de apoio em saúde mental para graduandos, sendo este um projeto de extensão que, entre 2018 e 2019, atendeu cerca de 700 estudantes, por meio de palestras e rodas de conversa com foco na psicoeducação, tendo a intenção de fomentar a criação de redes de apoio, identificação precoce dos casos de risco e realização de encaminhamentos a outros serviços especializados ${ }^{33}$.

Dentre as principais limitações apontadas, destacouse a adesão esporádica e a capacidade limitada de atendimento nos serviços gratuitos especializados, como as clínicas-escola de psicologia, barreiras estas que precisam ser enfrentadas a fim de se promover a QV e o desenvolvimento acadêmico, profissional e pessoal dos universitários, que por sua vez possam ser promotores de saúde para a sociedade na qual atuarão profissionalmente.

\section{CONCLUSÕES}

A amostra relatou alto índice de ansiedade, somado a diversos outros sintomas de sofrimento difuso, que podem ser interpretados no espectro dos chamados Transtornos Mentais Comuns, e que por sua vez têm efeitos prejudiciais na QV e podem incidir diretamente no rendimento acadêmico.

Os achados corroboram com outras pesquisas envolvendo processos de saúde-doença em graduandos da área da saúde. A despeito disso, sugere-se cautela na generalização dos resultados aqui apresentados, uma vez que estes fazem referência a um contexto específico, como é inerente às pesquisas de campo de cunho transversal. 
A existência de grupos interventivos que possam servir como redes de apoio, sugerem mudanças positivas tanto na $\mathrm{QV}$ quanto no rendimento acadêmico dos graduandos. Estes podem se constituir enquanto estratégias imediatas, a fim de serem complementadas e evoluídas por meio de outros estudos, como os longitudinais, e pensadas como políticas públicas e ações administrativas das instituições de ensino superior, uma vez que estas não podem se responsabilizar apenas pela instrução técnica do seu corpo discente, mas também pelo estado físico e mental que é fomentado durante sua formação e que reflete em como estes profissionais chegarão aos seus futuros postos de trabalho, a fim de servirem à sociedade com o que ali aprenderam, absorveram e elaboraram.

\section{REFERÊNCIAS}

1. Rios MGV, Mascarenha LVR, Souza KS, Olebar DTCR, Paiva MCE, Silveira AO. Adoecimento e sofrimento psíquico entre universitários: estado da arte. Rev. Humanidades e Inovação [Internet]. 2019 [acesso em 16 abr 2020];6(8):23-32. Disponível em: https://revista.unitins.br/index.php/humanidadeseinovacao/article/view/1259

2. Carleto CT, Moura RCD, Santos VS, Pedrosa LA. Adaptação à universidade e transtornos mentais comuns em graduandos de enfermagem. Rev. Eletrônica de Enfermagem [Internet]. 2018 [acesso em 10 abr 2020];20(1):111. Disponível em: https://revistas.ufg.br/fen/article/ view/43888/25414

3. Fonseca MLG, Guimarães MBL, Vasconcelos EM. Sofrimento difuso e transtornos mentais comuns: uma revisão bibliográfica. Rev. de APS [Internet] 2008 [acesso em 10 abr 2020];11(3):285-295. Disponível em: https://periodicos.uff. br/index.php/aps/article/view/14269

4. Fonseca MLG. Sofrimento difuso, transtornos mentais comuns e problema de nervos: uma revisão bibliográfica a respeito das expressões de mal-estar nas classes populares [Dissertação]. Rio de Janeiro: Fundação Oswaldo Cruz; 2007.
5. Gomes LF, Calixto MF. Saúde mental e ensino superior: a relação da universidade com o surgimento e/ou agravo de sofrimento mental em estudantes universitários [Trabalho de Conclusão de Curso]. Palmeira dos Índios: Faculdade CESMAC do Sertão; 2019.

6. Goldberg D, Huxley P. Common mental disorders: a bio-social model. New York: Tavistock/Routledge; 1992.

7. Perini JP, Delanogare E, Souza SA. Transtornos Mentais Comuns e aspectos psicossociais em universitários do sul do Brasil. Vittalle - Revista de Ciências da Saúde [Internet]. 2019 [acesso em 16 abr 2020];31(1):44-51. Disponível em: http://repositorio.furg.br/handle/1/7872

8. Santos ÉG, Siqueira MM. Prevalência dos transtornos mentais na população adulta brasileira: uma revisão sistemática de 1997 a 2009. J. Bras. Psiquiatr. [Internet]. 2010 [acesso em 16 abr 2020];3:238-246. Disponível em: http://www.scielo.br/scielo.php?script=sci_arttext\&pid=S004720852010000300011\&lng=en\&nrm=iso

9. Barros MJ, Borsari CMG, Fernandes AO, Silva A, Filoni E. Avaliação da qualidade de vida de universitários da área da saúde. Rev. Brasileira de Educação e Saúde [Internet]. 2017 [acesso em 9 abr 2020];7(1):16-22. Disponível em: https://editoraverde.org/gvaa.com.br/revista/index.php/REBES/article/view/4235

10. Carlesso JPP. Os desafios da vida acadêmica e o sofrimento psíquico dos estudantes universitários. Research, Society and Development [Internet]. 2020 [acesso em $10 \mathrm{abr}$ 2020];9(2):1-11. Disponível em: https://rsd.unifei.edu.br/index.php/rsd/article/view/2092/1721

11. Carleto CT, Cornélio MPM, Nardelli GG, Gaudenci EM, Haas VJ, Pedrosa LA. Saúde e qualidade de vida de universitários da área de saúde. Revista Família, Ciclos de Vida e Saúde no Contexto Social [Internet]. 2019 [acesso em 10 abr 2020];7(1):53-63. Disponível em: http://seer.uftm.edu. br/revistaeletronica/index.php/refacs/article/view/2966

12. Graner KM, Cerqueira ATAR. Revisão integrativa: sofrimento psíquico em estudantes universitários e fatores associados. Ciência \& Saúde Coletiva [Internet]. 2019 [acesso em 11 abr 2020];24(4):1327-1347. Disponível em: https:// www.scielosp.org/article/csc/2019.v24n4/1327-1346/pt/

13. Leão AM, Gomes IP, Ferreira MJM, Cavalcanti LPG. Prevalência e fatores associados à depressão e ansiedade entre estudantes universitários da área da saúde de um grande centro urbano do Nordeste do Brasil. Revista Bra- 
sileira de Educação Médica [Internet]. 2018 [acesso em 12 abr 2020];42(4):55-65. Disponível em: http://www.scielo.br/ scielo.php?pid=S0100 $-55022018000400055 \&$ script=sci_art text

14. Lopes MS, Sato MO, Sato RMS. Ansiedade em ambiente acadêmico: avaliação da sintomatologia de transtornos de ansiedade e do consumo de medicamentos entre estudantes de um centro universitário de Curitiba. Revista UNIANDRADE [Internet]. 2019 [acesso em 18 abr 2020];20(2):69-73. Disponível em: https://uniandrade.br/ revistauniandrade/index.php/revistauniandrade/article/ view/1332/1142

15. Oliveira AGM, Delben TVT, Sguarezi OGM, Spesotto MC, Hoffmann-Santos HD. Impacto da cefaleia sobre a qualidade de vida e o comportamento alimentar em estudantes universitários de cursos da área da saúde. Caderno de Publicações Univag [Internet]. 2019 [acesso em 13 abr 2020]; 1(10):86-102. Disponível em: http://www. periodicos.univag.com.br/index.php/caderno/article/viewFile/1445/1601

16. Paro CA, Bittencourt ZZLC. Qualidade de vida de graduandos da área da saúde. Revista Brasileira de Educação Médica [Internet]. 2013 [acesso em 13 abr 2020];37(3):365-375. Disponível em: http://www.scielo.br/ scielo.php?script=sci_arttext\&pid=S0100-55022013000300 009\&lang=pt

17. Suzuki NM, Nakae TK, Castro PC, Bonadia JC. Doença do Refluxo Gastroesofágico (DRGE): epidemiologia e qualidade de vida em estudantes universitários. Arq. Med. Hosp. Fac. Cienc. Med. Santa Casa São Paulo [Internet]. 2011[acesso em 16 abr 2020]; 56(2):65-67. Disponível em: http://189.125.155.35/index.php/AMSCSP/article/view/314.

18. Tamashiro EM, Amaral NA, Martins AH, Celeri EH, Bastos JFB. Desafios e sucessos de um serviço de saúde mental para estudantes da saúde. Revista de Medicina [Internet]. 2019 [acesso em 16 abr 2020];98(2):148-151. Disponível em: http://www.revistas.usp.br/revistadc/article/ view/155448

19. Almeida-Filho N. O que é saúde? Rio de Janeiro: Editora Fiocruz; 2011.

20. Minayo MCS, Hartz ZMA, Buss PM. Qualidade de vida e saúde: um debate necessário. Ciência \& Saúde Coletiva [Internet]. 2000 [acesso em 12 abr 2020];5(1):7-18. Disponível em: https://www.scielosp.org/pdf/csc/2000.v5n1/7-18/pt
21. Seidl EMF, Zannon CMLC. Qualidade de vida e saúde: aspectos conceituais e metodológicos. Cad. Saúde Pública [Internet]. 2004 [acesso em 16 abr 2020];20(2):580-588. Disponível em: http://www.scielo.br/scielo.php?script=sci_ arttext\&pid=S0102311X2004000200027\&lng=en\&nrm=iso

22. Kuhn T. A estrutura das revoluções científicas. Chicago: University of Chicago Press; 1962.

23. Pereira ÉF, Teixeira CS, Santos A. Qualidade de vida: abordagens, conceitos e avaliação. Rev. Bras. Educ. Fís. Esporte [Internet]. 2012[acesso em 16 abr 2020];26(2):241250. Disponível em: http://www.scielo.br/pdf/rbefe/ v26n2/07.pdf

24. Fontelles MJ. Bioestatística aplicada à pesquisa experimental (Volume 1). São Paulo: Livraria da Física; 2012.

25. Gil AC. Métodos e técnicas de pesquisa social. 6a ed. São Paulo: Atlas; 2008.

26. Bardin L. Análise de conteúdo. Lisboa: Edições 70, LDA; 2010.

27. Vizzotto MM, Jesus SN, Martins AC. Saudades de casa: indicativos de depressão, ansiedade, qualidade de vida e adaptação de estudantes universitários. Rev. Psicol. Saúde [Internet]. 2017 [acesso em 16 abr 2020];9(1):59-73. Disponível em: http://pepsic.bvsalud.org/scielo.php?script=sci arttext\&pid=S2177-093X2017000100004\&lng=pt

28. Langame AP, Chehuen Neto JÁ, Melo NB, Castelano ML, Cunha M, Ferreira RE. Qualidade de vida do estudante universitário e o rendimento acadêmico. Revista Brasileira em Promoção da Saúde [Internet]. 2016 [acesso em 11 abr 2020];29(3):313-325. Disponível em: https://www.redalyc. org/pdf/408/40849134002.pdf

29. Ariño DO, Bardagi MP. Relação entre fatores acadêmicos e a saúde mental de estudantes universitários. Revista Psicologia em Pesquisa [Internet]. 2018 [acesso em 9 abr 2020]; 12(3):44-53. Disponível em:https://periodicos. uff.br/index.php/psicologiaempesquisa/article/view/23791

30. Cardoso GMP, Veras RM, Coelho MTÁD, Figueiredo WN. Vida universitária e atividade física: um estudo sobre a produção acadêmica. Revista de Atenção à Saúde [Internet]. 2017 [acesso em 10 abr 2020];15(52):78-88. Disponível em: http://seer.uscs.edu.br/index.php/revista_ciencias_saude/ article/view/4522 
31. Gonçalves JS, Silva LL, Ninahuaman MFML, Abdala GA, Lima MOP. Perfil de risco cardiovascular em estudantes universitários. LifeStyle Journal [Internet]. 2018 [acesso em 11 abr 2020];5(2):91-108. Disponível em: https:// unasp.emnuvens.com.br/LifestyleJournal/article/view/1071

32. Vieira, JL, Romera LA, Lima MCP. Lazer entre universitários da área da saúde: revisão de literatura. Ciênc. Saúde Coletiva [Internet]. 2018 [acesso em 18 abr 2020]; 23(12):42214229. Disponível em: $\quad$ http://www.scielo.br/scielo.php?script=sci_ arttext\&pid=S141381232018001204221\&lng=en\&nrm=iso

33. Arenas DL, Viduani A, Zortea F, Bassols AMS. Pega leve - saúde mental do estudante universitário: um relato de experiência. Trab. En(Cena) [Internet]. 2019 [acesso em 9 abr 2020];4(2):519-530. Disponível em: https://sistemas.uft. edu.br/periodicos/index.php/encena/article/view/7440 